\title{
Postmortem lung biopsies from four patients with COVID-19 at a tertiary hospital in Cape Town, South Africa
}

\author{
C Bruce-Brand, ${ }^{1} \mathrm{MB}$ ChB, FC Path Anat (SA), DipRCPath (UK); B W Allwood, ${ }^{2} \mathrm{MB}$ ChB, DCH (SA), DA (SA), FCP (SA), \\ MMed (Int Med), PhD; C F N Koegelenberg, ${ }^{2} \mathrm{MB}$ ChB, MMed (Int Med), FCP (SA), PhD, FRCP (UK); \\ U Lalla, ${ }^{2} \mathrm{MB}$ ChB, MRCP, MMed (Int Med), FCP (SA); E Louw, ${ }^{2}$ MB ChB, MMed (Int Med), FCP (SA); A H Diacon, ${ }^{2,3}$ MD, PhD; \\ P T Schubert, ${ }^{1}$ MB ChB, MMed (Anat Path), FC Path Anat (SA), MSc MedSc (Cyto), MPhil (Paed Path) \\ ${ }^{1}$ Division of Anatomical Pathology, Department of Pathology, Faculty of Medicine and Health Sciences, Stellenbosch University and National \\ Health Laboratory Service, Tygerberg Hospital, Cape Town, South Africa \\ ${ }^{2}$ Division of Pulmonology, Department of Medicine, Faculty of Medicine and Health Sciences, Stellenbosch University and Tygerberg Hospital, \\ Cape Town, South Africa \\ ${ }^{3}$ TASK Applied Science, Cape Town, South Africa
}

Corresponding author: C Bruce-Brand (cbrucebrand@gmail.com)

\begin{abstract}
Background. An outbreak of a novel coronavirus in China in late 2019 has resulted in a global pandemic. The virus (SARS-CoV-2) causes a severe acute respiratory syndrome and had been responsible for $>14000$ deaths in South Africa (SA) at the time of writing, 30 August 2020. Autopsies in our setting have not been prioritised owing to the infective risks for staff, resulting in a lack of information on the histopathology of the disease in the SA setting. Postmortem biopsies are relatively quick and easy to perform and reduce the infective risk posed by full autopsies. Objectives. To determine whether postmortem biopsies of lung tissue could be used to determine cause of death in lieu of full autopsies in patients dying from COVID-19.

Methods. We performed postmortem biopsies of lung tissue on 4 patients with SARS-CoV-2 confirmed by reverse transcriptase polymerase chain reaction who died in the Tygerberg Hospital (Cape Town, SA) intensive care unit (ICU) in June - July 2020, in order to determine their cause of death. The biopsies were performed in the ICU with the necessary personal protective equipment within 2 hours after death. Clinical information was obtained from the hospital records and the histopathology was reviewed by two consultant histopathologists. Microbiology and electron microscopy were also performed on this tissue.

Results. All 4 patients were aged $>50$ years and had multiple comorbidities. Pulmonary pathology was present in only 3 cases, and the findings were surprisingly heterogeneous. One case demonstrated several findings including diffuse alveolar damage, extensive fibrin thrombi in pulmonary arteries with pulmonary infarction, organising pneumonia and bronchopneumonia. Other findings included type 2 pneumocyte hyperplasia, intra-alveolar macrophages and squamous metaplasia. An organising pneumonia was present in 2 other cases, although these findings were not deemed to be severe enough to be the cause of death. Fibrin thrombi were present in pulmonary arteries of 3 cases. One case showed no significant acute pulmonary pathology. The cause of death could only be determined in 1 case.

Conclusions. The pulmonary findings we observed are in keeping with those described in the international literature. However, the pathology was surprisingly heterogeneous between cases, and was only deemed severe enough to be the cause of death in 1 of 4 cases. While lung-targeted, standardised postmortem biopsies may be safe, easy to perform and provide useful insights into the disease, they are not suitable to replace full autopsies in determining cause of death.
\end{abstract}

S Afr Med J 2020;110(12):1195-1200. https://doi.org/10.7196/SAMJ.2020.v110i12.15290

An outbreak of a novel coronavirus caused by the severe acute respiratory syndrome coronavirus 2 (SARS-CoV-2) occurred in Wuhan, China, in late 2019. The World Health Organization designated the disease in humans as coronavirus disease 2019 (COVID-19) and subsequently declared a global pandemic. ${ }^{[1]}$ At the time of writing (30 August 2020), >14 000 deaths due to COVID-19 had been documented in South Africa (SA). ${ }^{[2]}$ The first description of the histological findings in pulmonary tissue in COVID-19 (in lobectomy specimens removed for primary carcinomas of the lung) showed oedema, type 2 pneumocyte hyperplasia, proteinaceous exudates, a patchy chronic inflammatory infiltrate, multinucleated giant cells and suspected viral inclusions within pneumocytes. ${ }^{[3]}$ Since this publication, numerous autopsy and postmortem biopsy studies have described histopathological features of the severe acute respiratory syndrome caused by this virus. These findings include diffuse alveolar damage, organising pneumonia, superimposed acute bronchopneumonia, type 2 pneumocyte hyperplasia, squamous metaplasia, congestion and fibrin thrombi and have been well summarised in a recent review by Al Nemer. ${ }^{[4-11]}$ The performance of hospital autopsies on confirmed COVID-19 cases has not been authorised in our setting, owing to safety concerns for mortuary staff and a lack of appropriately equipped mortuaries. There have therefore been no published reports of the histopathology findings from SA to date. Postmortem biopsies are quick, easy to perform and relatively safe compared with full autopsies and provided the only means of obtaining tissue for histopathology assessment in our setting.

\section{Objectives}

We hypothesised that by performing standardised lung-targeted postmortem biopsies we could determine the cause of death in patients who died due to complications of COVID-19 in an intensive care unit (ICU) in Cape Town, SA. We also aimed to describe the clinical and histological findings of all included cases. 


\section{Methods}

Postmortem samples were taken from 4 adult patients who tested positive for SARS-CoV-2 by reverse transcriptase polymerase chain reaction and subsequently died in the Tygerberg Hospital ICU between June and July 2020 as a result of COVID-19. Verbal delayed proxy consent was obtained from the families of these patients. Postmortem biopsies were performed in the ICU by one of the treating doctors within 2 hours after death. Appropriate personal protective equipment as dictated by the hospital safety guidelines was worn by those performing the biopsies. Core needle biopsies were taken from each lung lobe (without imaging guidance) followed by a single open lung biopsy of the right lung, in the mid-axillary line and 4th or 5th intercostal space. Each specimen was placed into an individually labelled specimen jar and macroscopically assessed for adequacy by a member of the research team. The specimens for histopathology were fixed in $10 \%$ buffered formalin and processed in the histopathology laboratory after appropriate fixation. Tissue was also submitted for microbiology (one core from the upper lobe of each lung in normal saline) and electron microscopy (one fragment from the lower lobe of each lung in glutaraldehyde). The histology was assessed by two consultant histopathologists at the National Health Laboratory Service. Clinical information such as age, gender, comorbidities, duration of illness and ICU admission, methods of ventilation and treatment (antimicrobials, anticoagulant therapy and corticosteroid therapy) were captured from the hospital records. Ethical approval for this study was provided by the Stellenbosch University Health Research Ethics Committee.

\section{Findings}

\section{Clinical characteristics}

The 4 patients were 3 women, all aged 58 years, and 1 man, aged 65 years. All had comorbidities, including hypertension and obesity (4/4), type 2 diabetes mellitus (3/4), atrial fibrillation (1/4), epilepsy (1/4) and hypercholesterolaemia (1/4). None of the patients had HIV infection. The duration of ICU admission ranged from 2 days to 1 week, with all patients initially receiving ventilation in the form of high-flow nasal oxygen. Three were ultimately intubated and mechanically ventilated. All 4 had elevated acute-phase reactants and raised D-dimers. Treatment included antimicrobials, anticoagulant therapy (clexane and/or aspirin) and corticosteroid therapy, and details are presented with the summarised clinical features in Table 1.

\section{Histology}

The histopathology findings are summarised in Table 2. Only 1 of the 4 patients demonstrated features of diffuse alveolar damage with hyaline membranes (Fig. 1). This patient (patient 3) also

\begin{tabular}{|c|c|c|c|c|}
\hline Clinical parameters & Patient 1 & Patient 2 & Patient 3 & Patient 4 \\
\hline Age (years) & 58 & 58 & 65 & 58 \\
\hline Sex & Female & Female & Male & Female \\
\hline \multirow[t]{5}{*}{ Comorbidity } & HPT & HPT & HPT & HPT \\
\hline & Type 2 DM & Type 2 DM & Type 2 DM & Obesity \\
\hline & Obesity & Obesity & Obesity & \\
\hline & $\mathrm{AF}$ & & Epilepsy & \\
\hline & & & HCL & \\
\hline Duration of symptoms prior to admission (days) & 3 & 2 & 3 & 7 \\
\hline Duration of ICU admission (days) & 7 & 2 & 5 & 3 \\
\hline \multicolumn{5}{|l|}{ Method of ventilation (days) } \\
\hline HFNC & 7 & 1 & 1 & 2 \\
\hline NIV & 0 & 0 & 0 & 0 \\
\hline IPPV & 0 & 1 & 4 & 1 \\
\hline \multirow[t]{4}{*}{ Antimicrobial use (type) } & Augmentin & Augmentin & Augmentin & Augmentin \\
\hline & Azithromycin & Azithromycin & Azithromycin & Azithromycin \\
\hline & & & Meropenem & Vancomycin \\
\hline & & & Vancomycin & \\
\hline \multicolumn{5}{|l|}{ Anticoagulation therapy } \\
\hline Clexane & Yes (therapeutic) & Yes (therapeutic) & Yes (therapeutic) & No \\
\hline Aspirin & No & No & Yes & Yes \\
\hline Corticosteroid use (type) & Dexamethasone & Dexamethasone & Dexamethasone & Dexamethasone \\
\hline \multicolumn{5}{|l|}{ Full blood count } \\
\hline WCC $\left(\times 10^{9} / \mathrm{L}\right)$ & 16.2 & 14.32 & 11.4 & 34.4 \\
\hline $\mathrm{Hb}(\mathrm{g} / \mathrm{dL})$ & 9.2 & 14.2 & 10.8 & 10.2 \\
\hline Plt $\left(\times 10^{9} / \mathrm{L}\right)$ & 204 & 95 & 98 & 367 \\
\hline Neut $\left(\times 10^{9} / \mathrm{L}\right)$ & 13.9 & 12.76 & 10.4 & 30.4 \\
\hline Lymph $\left(\times 10^{9} / \mathrm{L}\right)$ & 1.54 & 1.03 & 0.48 & 2.27 \\
\hline \multicolumn{5}{|l|}{ Acute-phase markers } \\
\hline $\mathrm{CRP}(\mathrm{mg} / \mathrm{L})$ & 29 & 345 & 434 & 123 \\
\hline РCT $(\mu \mathrm{g} / \mathrm{L})$ & 1.03 & 51.64 & 5.45 & 0.38 \\
\hline D-dimer (mg/L) & 0.93 & 2.04 & 17.6 & 1.21 \\
\hline
\end{tabular}


Table 2. Summary of histological findings

\begin{tabular}{|c|c|c|c|c|}
\hline & Patient 1 & Patient 2 & Patient 3 & Patient 4 \\
\hline Acute inflammation (neutrophils) & Absent & Absent & Present & Absent \\
\hline Interstitial lymphocytes & Absent & Absent & Present & Present \\
\hline Intra-alveolar macrophages & Present, focal & Absent & Present & Present \\
\hline Type 2 pneumocyte hyperplasia & Absent & Absent & Present & Present \\
\hline Multinucleated giant cells & Absent & Absent & Present & Present \\
\hline Intra-alveolar oedema & Present & Absent & Present & Absent \\
\hline Interstitial oedema & Absent & Absent & Absent & Absent \\
\hline Squamous metaplasia & Present & Absent & Absent & Absent \\
\hline \multicolumn{5}{|l|}{ Fibrin thrombi } \\
\hline Pulmonary arteries & Present, focal & Absent & Present, extensive & Present \\
\hline Pulmonary veins & Absent & Absent & Absent & Absent \\
\hline \multicolumn{5}{|l|}{ Congestion } \\
\hline Pulmonary arteries & Absent & Absent & Absent & Absent \\
\hline Pulmonary veins & Absent & Absent & Absent & Absent \\
\hline Capillaries & Absent & Absent & Present & Absent \\
\hline Alveolar haemorrhage & Absent & Absent & Present & Absent \\
\hline Hyaline membranes & Absent & Absent & Present & Absent \\
\hline Collapsed alveoli & Absent & Absent & Absent & Absent \\
\hline Pleural changes & Absent & Marked thickening & Absent & Absent \\
\hline Arterial hyalinisation & Absent & Absent & Absent & Present \\
\hline Organising pneumonia & Present & Absent & Present & Present \\
\hline Other findings & - & $\begin{array}{l}\text { Extensive carbon } \\
\text { pigment deposition }\end{array}$ & $\begin{array}{l}\text { Pulmonary } \\
\text { infarction }\end{array}$ & - \\
\hline
\end{tabular}

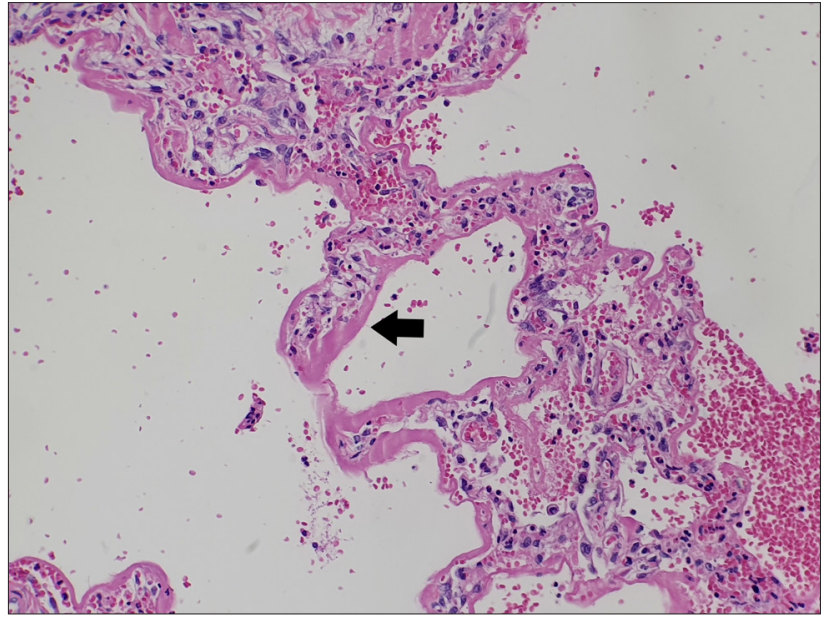

Fig. 1. Alveolar spaces are lined by thick hyaline membranes (arrow). The interstitium is oedematous and scattered lymphocytes are present (haematoxylin and eosin $\times 200$ ).

demonstrated extensive fibrin thrombi within pulmonary arteries (Fig. 2A), capillary congestion and pulmonary infarction (Fig. 3), and had markedly elevated D-dimer levels of $17.6 \mathrm{mg} / \mathrm{L}$. An organising pneumonia as well as a bronchopneumonia were present in this case (Figs 4A and 5). No organisms were cultured. Patients 1 and 4 also demonstrated organising pneumonia, although these findings were not marked (Fig. 4B). Squamous metaplasia was only seen in 1 case (patient 1 - Fig. 6). Fibrin thrombi were seen in pulmonary arteries in 3 cases (patients 1, 3 and 4), all of whom had received anticoagulant therapy (Fig, 2B). One case had no acute pulmonary findings (patient 2), but the background lung showed extensive carbon pigment deposition and thickened pleura. Electron microscopy was performed on all 4 cases, but viral particles could not be demonstrated. No bacterial or fungal organisms were cultured in any of the cases.

\section{Discussion}

We describe the pulmonary histopathological findings in 4 cases of fatal COVID-19 obtained though postmortem biopsies of lung tissue, which demonstrated varied pathology between cases, including interstitial lymphocytes, intra-alveolar macrophages and oedema, multinucleated giant cells and type 2 pneumocyte hyperplasia (Fig. 7). The clinical parameters of these patients are in keeping with the expected patient profile described so far in fatal COVID19 , including the presence of multiple comorbidities and older age. However, in 3 of the 4 cases, the pulmonary findings were deemed of insufficient severity to be attributed as the cause of death, with only mild changes observed in 2 cases and no significant acute pulmonary pathology seen in 1. A limited number of postmortem lung biopsies therefore does not reliably demonstrate the cause of death in our series of patients dying from COVID-19 in an ICU.

The histopathology of the pulmonary tissue showed changes sufficient to be deemed the cause of death in only 1 patient (patient 3 ); these included diffuse alveolar damage, type 2 pneumocyte hyperplasia, extensive fibrin thrombi, capillary congestion, organising pneumonia and bronchopneumonia. These findings have been described in the setting of COVID-19. In an autopsy series of 21 patients in Switzerland, the most prominent findings described included exudative diffuse alveolar damage, pulmonary capillary congestion and reactive pneumocytes. ${ }^{[10]}$ Additionally, microthrombi, pulmonary embolism and bronchopneumonia were seen in a subset of cases. ${ }^{[10]}$

We noted multinucleated giant cells (Fig. 8), also described in other studies, which have been shown to be syncytial type 2 pneumocytes (positive with thyroid transcription factor 1 immunohistochemistry). ${ }^{[10]}$ Squamous metaplasia within alveoli, an 

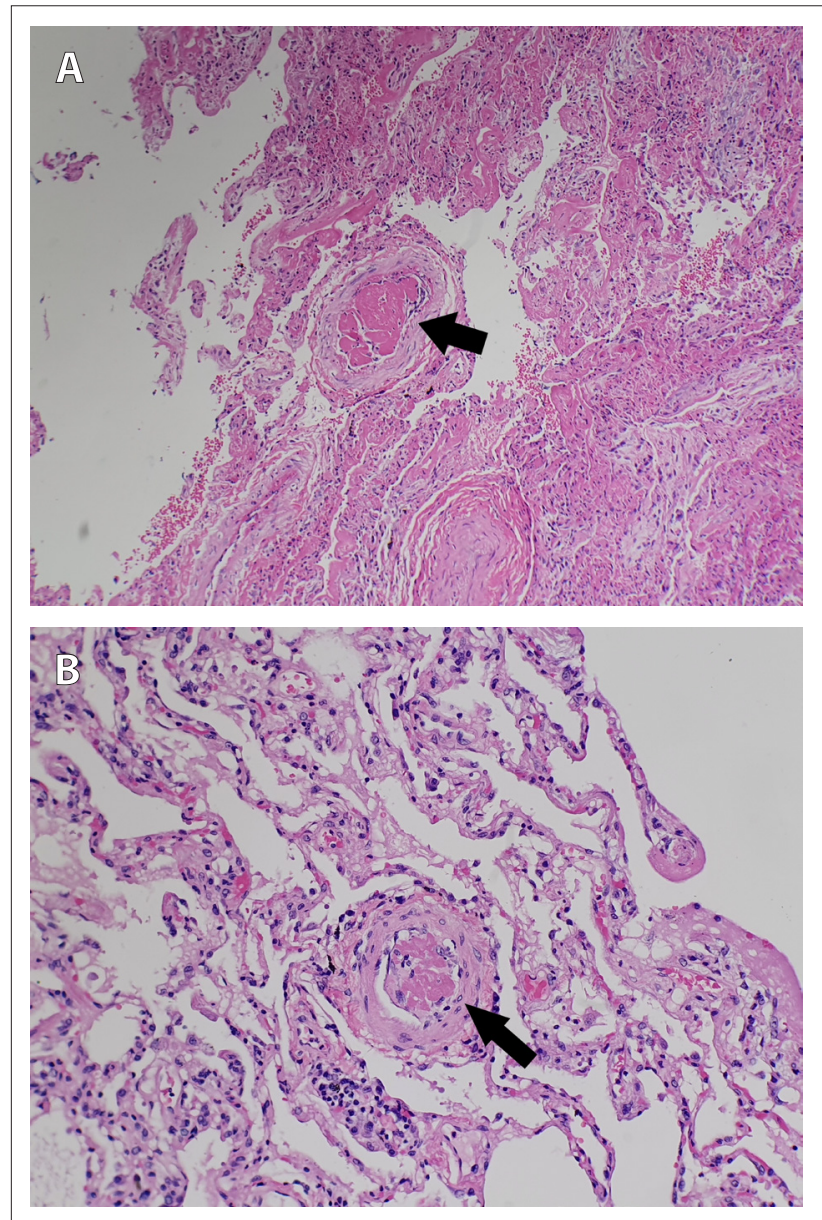

Fig. 2. A: A fibrin thrombus is present within a pulmonary artery (arrow) (haematoxylin and eosin $\times 100$ ). B: A fibrin thrombus in a pulmonary artery (arrow). The background lung tissue is relatively normal in this case (haematoxylin and eosin $\times 200$ ).

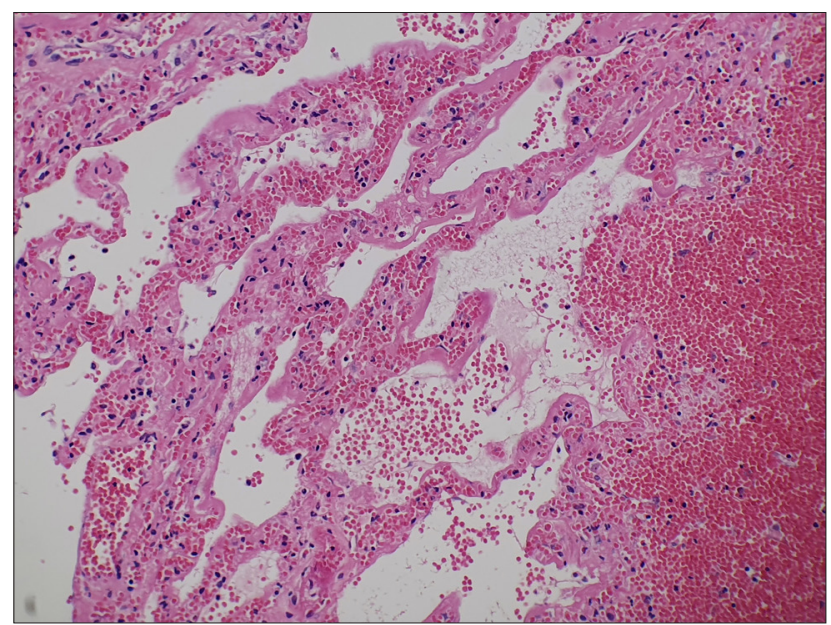

Fig. 3. The lung parenchyma adjacent to the thrombus in Fig. $2 \mathrm{~A}$ is infarcted. The cellular detail of the cells lining the alveolar spaces is lost and there is haemorrhage in keeping with haemorrhagic infarction (haematoxylin and $\operatorname{eosin} \times 100)$.

unusual finding, was seen in 1 case (Fig. 6). This was described in a few cases of COVID-19 in the Northern Italy series ${ }^{[12]}$ and has been described in other viral infections such as severe acute respiratory syndrome (SARS), particularly with a duration of illness beyond
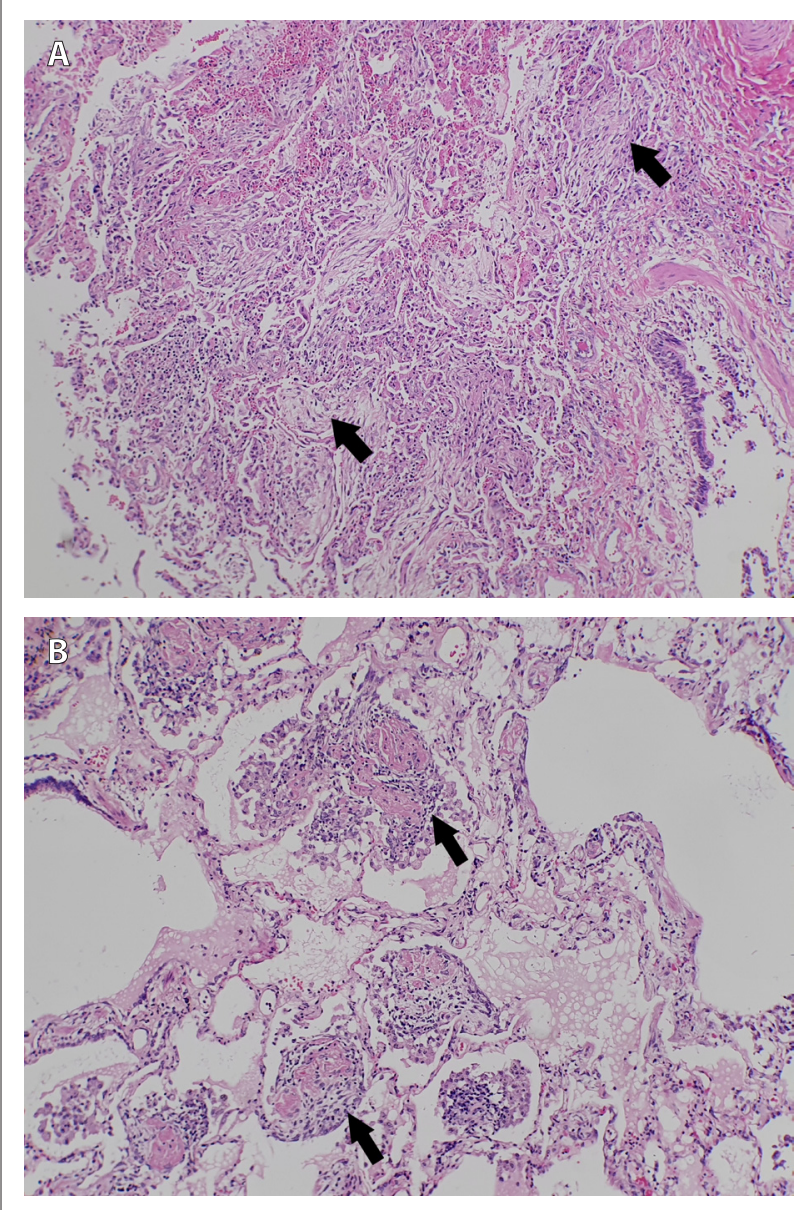

Fig. 4. A: Organising pneumonia is present. The alveolar spaces are filled with fibromyxoid material (arrows) (haematoxylin and eosin $\times 100$ ). B: This lung tissue demonstrates plugs of fibromyxoid material within alveolar spaces (arrows). The background lung appears relatively well preserved (haematoxylin and eosin $\times 100$ ).

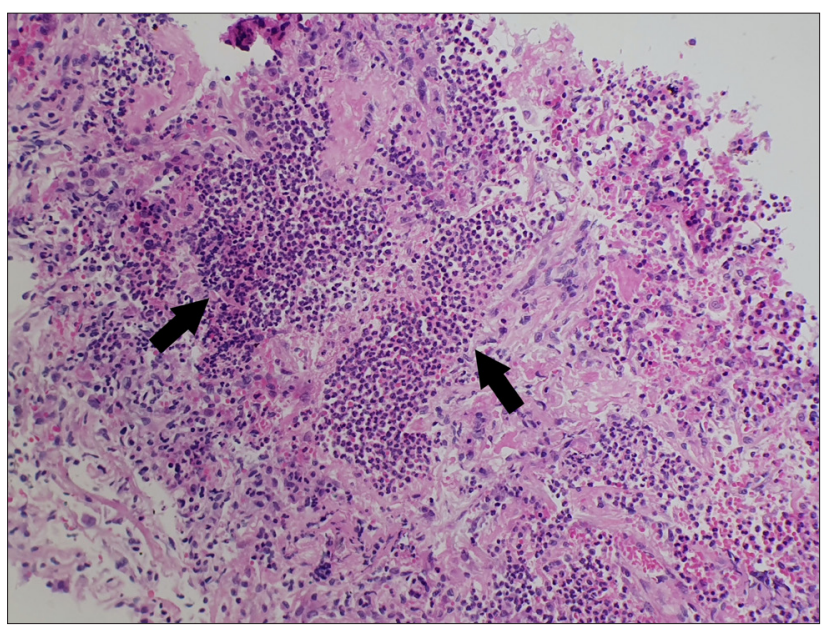

Fig. 5. This core of lung tissue demonstrates an acute bronchopneumonia with extensive accumulation of neutrophils within alveolar spaces (arrows) (haematoxylin and eosin $\times 200$ ).

14 days. ${ }^{[13,14]}$ Interestingly, hyaline membranes were not prominent in 3 of the 4 cases, and alveolar collapse was not observed.

Evidence suggests that COVID-19 causes an intense inflammatory reaction marked by upregulation of cytokines which result in lung 


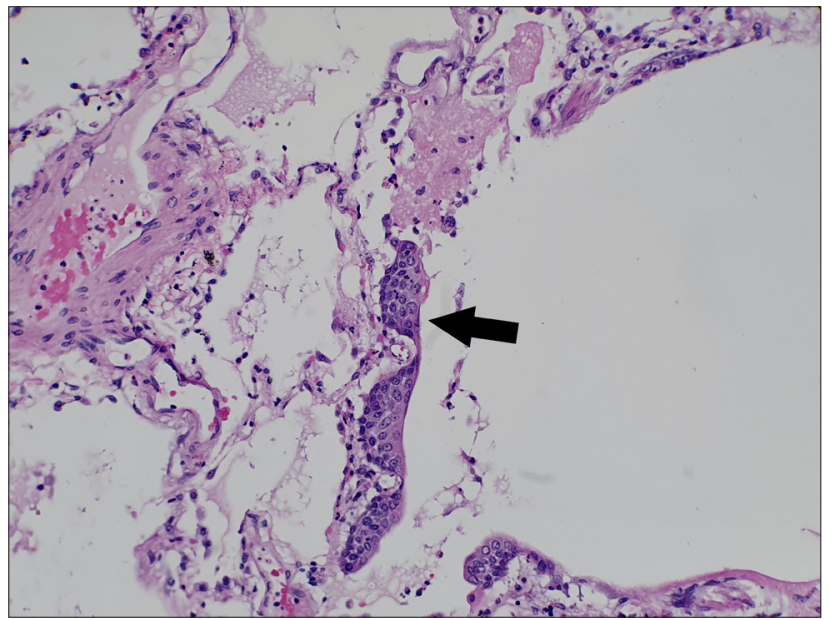

Fig. 6. Squamous metaplasia of the alveolar spaces is evident (arrow) (haematoxylin and eosin $\times 100$ ).

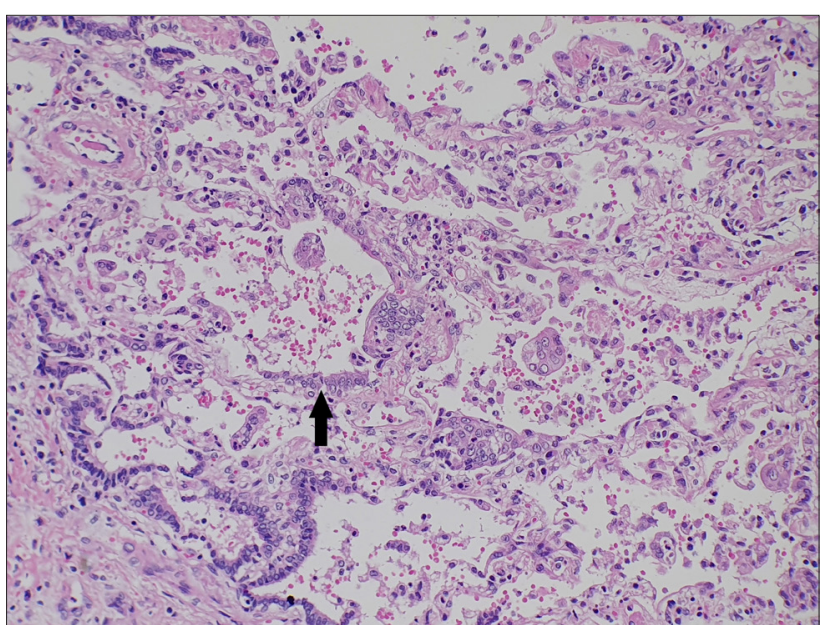

Fig. 7. Type 2 pneumocyte hyperplasia is present (arrow). The interstitium is expanded with oedema, and lymphocytes and multinucleated cells are present (haematoxylin and eosin $\times 200$ ).

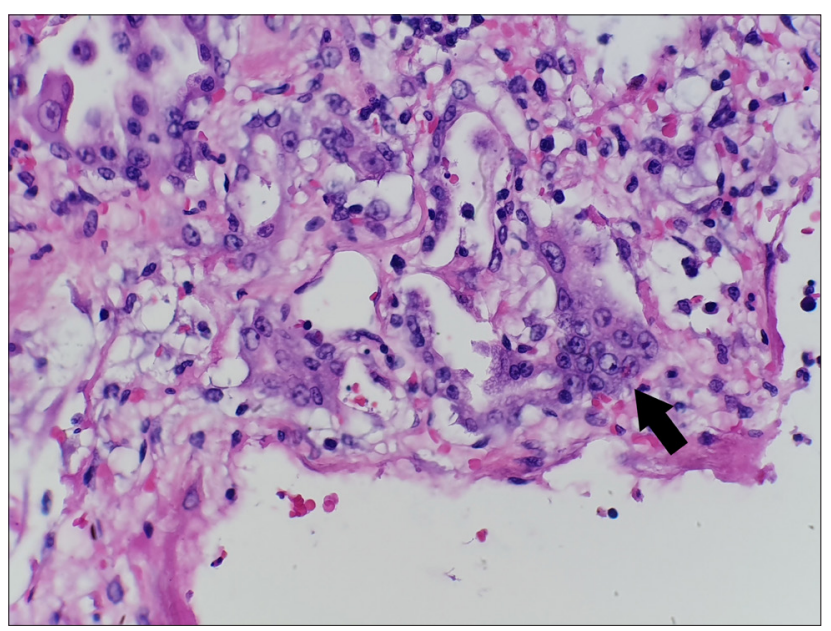

Fig. 8. The multinucleated cells at higher magnification (arrow). These cells are positive for thyroid transcription factor 1, indicating that they are pneumocytes rather than macrophages (haematoxylin and eosin $\times 400$ ).

injury. ${ }^{[15,16]}$ Corticosteroid therapy modulates such host responses and has been shown to reduce hospital mortality in patients with severe COVID-19. ${ }^{[17]}$ All 4 patients received corticosteroid therapy from the time of admission to the ICU. The presence of organising pneumonia in 3 cases and the absence of diffuse alveolar damage in 2 of these may be explained by the effectiveness of the corticosteroid therapy.

Much has been written regarding the coagulopathy and endothelial damage caused by COVID-19. ${ }^{[18]}$ In our patients, 3 of the 4 had fibrin thrombi in vessels with elevated D-dimer levels, despite all being on anticoagulant therapy. Patient 3 had a markedly elevated D-dimer reading $(17.6 \mathrm{mg} / \mathrm{L})$ and showed pulmonary infarction, probably due to the extensive fibrin thrombi seen. The finding of pulmonary infarction has not been described in COVID-19 to our knowledge, but has been described in SARS-CoV (severe acute respiratory syndrome coronavirus). ${ }^{[13,14]}$

Bronchopneumonia was observed in 1 case, and 2 cases showed markedly raised procalcitonin values, yet no bacterial or fungal organisms were observed or cultured. Since bronchopneumonia may be patchy, there may be sampling bias with performance of core needle biopsies. All 4 patients had received antibiotic therapy, which could potentially have sterilised samples prior to collection. No viral particles could be seen on electron microscopy within pneumocytes, macrophages or endothelial cells.

\section{Study limitations}

This series has a number of limitations, first being the small sample size, which limits our ability to draw conclusions. Despite the high mortality figures, this small sample reflects issues regarding the local policies for obtaining postmortem specimens. Secondly, owing to safety concerns, full postmortem examinations were not authorised, and lung biopsies remained the only option available to researchers. Despite samples being obtained from multiple lobes of both lungs within 2 hours of death to minimise tissue autolysis, sampling error may still have occurred. Sampling was done blindly without imaging guidance and abnormal areas of lung were therefore not specifically targeted. Lack of inclusion of patients with HIV infection limits the extrapolation of these findings to immunocompromised individuals.

Despite these limitations, the histological findings in these cases were remarkably varied between patients, despite phenotypically similar clinical disease profiles. In 3 cases the pulmonary findings were deemed mild, and death in these cases was probably not due to the observed pulmonary complications of COVID-19. The lack of significant pulmonary findings in 3 cases emphasises the need for performance of full medical autopsies for patients dying of COVID-19, in order to gain better understanding of the spectrum of pathology and causes of death, with a view to improving outcomes. More histopathology specimens are specifically needed in HIV-positive cases, which may not be the same as in immunocompetent patients.

\section{Conclusions}

The spectrum of pulmonary pathology seen in our setting in patients dying from complications of COVID-19 includes diffuse alveolar damage, organising pneumonia, superimposed bronchopneumonia, fibrin thrombi, type 2 pneumocyte hyperplasia and squamous metaplasia. These findings are in keeping with those described in the international literature. However, the pulmonary findings were severe enough to explain the cause of death in only 1 of the 4 cases and were heterogeneous between cases. While performance of a limited prespecified number of postmortem lung biopsies may reduce safety concerns in the setting of a highly infectious disease, the pathology and treatment-induced changes are too varied to be captured by such an approach. This varied pathology highlights the need for performance of full autopsies in order to accurately determine the cause of death in patients dying with COVID-19 and the need for availability of appropriate facilities to conduct such autopsies. 


\section{Declaration. None.}

Acknowledgements. The authors would like to thank the families of these patients for their contribution to science, Prof. Keymanthri Moodley for her tireless efforts and support in navigating the ethical issues of this study, and Prof. G Walzl for his support.

Author contributions. CB-B was principal investigator. All authors contributed to the performance of this study and to the write-up of this manuscript.

Funding. Faculty of Health Sciences, Stellenbosch University.

Conflicts of interest. None.

1. World Health Organisation. Coronavirus Disease 2019 (COVID-19) situation report - 51. 11 March 2020. http://www.who.int/docs/default-source/coronaviruse/situation-reports/20200311-sitrep-51covid-19.pdf?sfvrsn=1ba62e57_10 (accessed 7 September 2020).

2. Department of Health, Republic of South Africa. Media release: Health Minister Mkhize COVID-19 update (30 August 2020). http://www.health.gov.za/index.php/2014-03-17-09-48-36/2014-03-17-09update (30 August 2020). http://ww

3. Tian S, Hu W, Niu L, Liu H, Xu H, Xiao SY. Pulmonary pathology of early-phase 2019 novel coronavirus (COVID-19) pneumonia in two patients with lung cancer. J Thorac Oncol 2020;15(5):700-704. https:// doi.org/10.1016/.j.tho.2020.02.010

4. Xu Z, Shi L, Wang Y, et al. Pathological findings of COVID-19 associated with acute respiratory distress. Lancet Respir Med 2020;8(4):420-422. https://doi.org/10.1016/S2213-2600(20)30076-X

5. Barton L, Duval E, Stroberg E, Ghosh S, Mukhopadhyay S. COVID-19 autopsies, Oklahoma, USA. Am J Clin Pathol 2020;153(6):725-733. https://doi.org/10.1093/ajcp/aqaa062

6. Fox SE, Akmatbekov A, Harbert JL, Li G, Quincy Brown J, vander Heide RS. Pulmonary and cardiac pathology in African American patients with COVID-19: An autopsy series from New Orleans. Lancet Respir Med 2020;8(7):681-686. https://doi.org/10.1016/S2213-2600(20)30243-5

7. Zhang T, Sun L, Feng R. Comparison of clinical and pathological features between severe acute respiratory syndrome and coronavirus disease 2019. Zhonghua Jie He He Hu Xi Za Zhi 2020;43(6):496502. https://doi.org/10.3760/cma.j.cn112147-20200311-00312
8. Wichmann D, Sperhake JP, Lütgehetmann M, et al. Autopsy findings and venous thromboembolism in patients with COVID-19: A prospective cohort study. Ann Intern Med 2020;173(4):268-277. https:// oi.org/10.7326/M20-2003

9. Yao X, Li T, He Z. A pathological report of three COVID-19 cases by minimally invasive autopsies. Zhonghua Bing Li Xue Za Zhi 2020;49(5):411-417. https://doi.org/10.3760/ autopsies. Zhonghua Bing

10. Menter T, Haslbauer JD, Nienhold R, et al. Postmortem examination of COVID-19 patients reveals diffuse alveolar damage with severe capillary congestion and variegated findings in lungs and other organs suggesting vascular dysfunction. Histopathology 2020 (epub 4 May 2020). https://doi. org/10.1111/his.14134

11. Al Nemer A. Histopathologic and autopsy findings in patients diagnosed with coronavirus disease 2019 COVID 19): What we know so far based on correlation with clinical, morphologic and pathobiological aspects. Adv Anat Pathol 2020 (epub 23 July 2020). https://doi.org/10.1097/PAP.0000000000000276

12. Carsana L, Sonzogni A, Nasr A, et al. Pulmonary post-mortem findings in a series of COVID-19 cases from northern Italy: A two-centre descriptive study. Lancet Infect Dis 2020;20(10):1135-1140. https:// doi.org/10.1016/S1473-3099(20)30434-5

13. Franks TJ, Chong PY, Chui P, et al. Lung pathology of severe acute respiratory syndrome (SARS): A study of 8 autopsy cases from Singapore [published correction appears in Hum Pathol A study of 8 autopsy cases from Singapore Lpublished correction appears in Hum Patho

14. Hwang DM, Chamberlain DW, Poutanen SM, Low DE, Asa SL, Butany J. Pulmonary pathology of severe acute respiratory syndrome in Toronto. Mod Pathol 2005;18(1):1-10. https://doi.org/10.1038/ severe acute respiratory syndrome in Toronto. Mod Pathol 2005;18(1):1-10. https://doi.org/10.1038/ modpathol. 3800247

15. Mehta P, McAuley DF, Brown M, et al. COVID-19: Consider cytokine storm syndromes and immunosuppression. Lancet 2020;395(10229):1033-1034. https://doi.org/10.1016/S01406736(20)30628-0

16. Zhang W, Zhao Y, Zhang F, et al. The use of anti-inflammatory drugs in the treatment of people with severe coronavirus disease 2019 (COVID-19): The perspectives of clinical immunologists from China. Clin Immunol 2020;214:108393. https://doi.org/10.1016/j.clim.2020.108393

17. Bani-Sadr F, Hentzien M, Pascard M, et al. Corticosteroid therapy for patients with COVID-19 pneumonia: A before-after study. Int J Antimicrob Agents 2020;56(2):106077. https://doi. org/10.1016/j.jiantimicag.2020.106077

18. Ackermann M, Verleden SE, Kuehnel M, et al. Pulmonary vascular endothelialitis, thrombosis, and angiogenesis in Covid-19. N Engl J Med 2020;383(2):120-128. https://doi.org/10.1056/ NEJMoa2015432

Accepted 7 October 2020. 